\title{
Special issue: Evidence based policy making — selected papers of the 2020 Annual Meeting of the Austrian Economic Association
}

\author{
Jesus Crespo Cuaresma ${ }^{1} \cdot$ Harald Oberhofer $^{2} \cdot$ Rupert Sausgruber $^{3}$
}

Published online: 24 June 2021

(C) The Author(s), under exclusive licence to Springer Science+Business Media, LLC, part of Springer Nature 2021

The overarching theme of the 2020 Annual Meeting of the Austrian Economic Association $(\mathrm{NOeG})$, hosted at the Vienna University of Economics and Business, was Evidence-Based Economic Policy Making, a topic that has gained extraordinary impetus over the last decade in the context of the so-called credibility revolution in economics (see Angrist et al. 2017).

Several developments in the discipline have contributed to the topic becoming central in the academic discussion. On the one hand, the rapid improvement in the availability of high-quality (especially administrative) data for economic research has enabled much more rigorous analysis of the causal effects of policies and quantification of impacts. On the other hand, there have been significant parallel advances in the methodological toolbox for identifying such effects (variations of differencesin-differences designs, or synthetic control methods, for instance), and new econometric methods aimed at quantifying causal linkages have become standard in virtually all sub-disciplines of economics. In order to ensure the precision and external validity of policy evaluation efforts, assessing potentially heterogeneous causal effects of policies across different population groups and over time has been at the core of many recent methodological improvements in the literature.

Harald Oberhofer

harald.oberhofer@wu.ac.at

Jesus Crespo Cuaresma

jesus.crespo.cuaresma@wu.ac.at

Rupert Sausgruber

rupert.sausgruber@wu.ac.at

1 Vienna University of Economics and Business, International Institute for Applied Systems Analysis, Austrian Institute of Economic Research, CESifo, Welthandelsplatz 1, A-1020 Vienna, Austria

2 Vienna University of Economics and Business, Austrian Institute of Economic Research, CESifo, Welthandelsplatz 1, A-1020 Vienna, Austria

3 Vienna University of Economics and Business, Welthandelsplatz 1, 1020 Vienna, Austria 
Rigorous, science-based evaluations of public policy help improve societal outcomes by enabling the selection of policy instruments to achieve public goals as effectively as possible. Whether the knowledge gained in research can actually contribute to improving the living standards of citizens depends on whether policymakers understand and use of the results of scientific research. The inherent complexity of policy decision-making structures may prevent the interface between science and policy from functioning smoothly and evidence-based policies from actually being implemented, even when the results are understood and accepted by political leaders. A recent empirical analysis by Hjort et al. (2021) conducted in Brazil, provides robust evidence that policymakers not only value research but also actually change their beliefs about the effectiveness of policies and tend to implement empirically validated policy instruments when confronted with scientific results. These insights suggest that the results of quantitative policy evaluation can serve as triggers of policy changes that, in turn, can significantly improve the well-being of society.

The papers published in this special issue represent a small selection of the topics addressed in modern research aimed at informing policymakers about the consequences of alternative economic policies. The special issue includes papers on the effects of fiscal policy measures in Slovenia, the trade and welfare effects of the Economic Partnership Agreement signed between the EU and Japan, the impact of ethnic heterogeneity and military conflicts on regional consumption risk-sharing in the Ukraine, and the labor supply effects of a (planned) reform in the Austrian social security system.

In the first paper of this special issue, Neck et al. (2021) study the economic effects of alternative fiscal policy measures in Slovenia using SLOPOL10, a medium-sized macroeconomic model tailored to the Slovenian economy. The authors are interested in comparing the growth effects of demand-side versus supply-sides fiscal policy measures over a time window spanning the years from 2020 to 2030. Given the medium-run perspective of their research question, the main findings suggest that a combination of demand-side and supply-side fiscal policy measures might be more efficient as purely demand-side policies as the former policy mix also increases potential and not only actual output. In particular, Neck et al (2021) identify policies that foster research and development activities and positively contribute to the level of education as being most effective for increasing medium-run GDP in Slovenia.

On February 1st, 2019 the largest trade agreement of EU with an Asian economy entered into force. The Economic Partnership Agreement (EPA) with Japan affects a total volume of almost 100 Billion Euros of EU exports annually and can be considered one of the deepest trade agreements the EU have ever signed until today. ${ }^{1}$ Grübler et al. (2021) provide an in-depth analysis of the trade and welfare effects of the EPA and particularly concentrate on the reduction in non-tariff barriers for trade. Using counterfactual scenario analyses based on a standard structural gravity model, the authors quantify the effects of the EPA. With respect to the expected GDP effects, this agreement can be expected to only have small effects, which are, however, larger for Japan.

\footnotetext{
${ }^{1}$ See e.g., https://ec.europa.eu/trade/policy/in-focus/eu-japan-economic-partnership-agreement/ (last accessed on June 13th, 2021).
} 
Over the last years, Ukraine has experienced sustained war tensions driven smallscale military conflicts and ethnic tensions. The third paper of this special issue by Fidrmuc et al. (2021) studies the consequences of this development for consumption risk sharing across Ukrainian regions. In the context of this study, a high degree of consumption risk sharing implies a smoothing of consumption across different regions following an income shock. For the years from 2003 to 2016, the authors identify important consumption risk sharing across all Ukrainian regions, whereby this phenomenon seems to be more important in regions with strong Russian minorities. This heterogeneity in the effects can be explained by a favorable treatment of these regions by Russia. It is also found that these patterns of consumption-risk sharing have changed due to the recent geopolitical conflict in east Ukraine.

The paper by Christl and de Poli (2021) studies the labor supply effects of changes in social assistance payments using EUROMOD, a tax-benefit microsimulation model for the member states of the EU. Over the last years, EUROMOD has become one of the main tools for ex-ante economic analyses of labor market and social policy reform proposals within the EU. In the published special issue article, the two authors apply EUROMOD in order to study the heterogeneous behavioral responses with regard changes in social assistance payments. Their findings suggest that labour supply elasticities vary substantially across gender and household types. The paper uses these elasticities to study the overall labor market effects from a proposed Austrian reform called "Neue Sozialhilfe". This program aimed at limiting social assistance payments for some specific groups including larger families and persons with asylum but poor languages skills. The findings from the simulation exercise suggest that the labor market reactions are especially strong for men and migrants and that labour supply would slightly increase in the aftermath of such a reform, at least at its intensive margin.

\section{References}

Angrist J, Azoulay P, Ellison G, Hill R, Lu SF (2017) Economic research evolves: fields and styles. Am Econ Rev 107(5):293-297

Christl M, De Poli S (2021) Trapped in inactivity? Social assistance and labour supply in Austria. Empirica. https://doi.org/10.1007/s10663-021-09507-8

Fidrmuc J, Moroz S, Reck F (2021) Regional risk-sharing in Ukraine. Empirica. https://doi.org/10.1007/ s10663-020-09500-7

Grübler J, Reiter O, Stehrer R (2021) On the new gold standard in EU trade integration: reviewing the EUJapan EPA. Empirica. https://doi.org/10.1007/s10663-021-09506-9

Hjort J, Moreira D, Rao G, Santini JF (2021) How research affects policy: experimental evidence from 2,150 Brazilian municipalities. Am Econ Rev 111(5):1442-1480

Neck R, Weyerstrass K, Blueschke D et al (2021) Demand-side or supply-side stabilisation policies in a small euro area economy: a case study for Slovenia. Empirica. https://doi.org/10.1007/s10663-21-09503-y

Publisher's Note Springer Nature remains neutral with regard to jurisdictional claims in published maps and institutional affiliations. 